\title{
ULCERA DE MARJOLIN, REPORTE DE UN CASO CLÍNICO.
}

\section{MARJOLIN'S ULCER: A CASE REPORT}

\author{
Dr. Villalba; Willian*; Dr. Ortellado; Juan B. ${ }^{\star *}$; \\ Dra. Duarte; Romina ${ }^{\star * *}$; Dr. Campuzano; Miguel ${ }^{\star * * *}$
}

\begin{abstract}
RESUMEN
El término úlcera de Marjolin, engloba todo proceso maligno que surja a partir de un tejido cicatricial, $5 \%$ de los carcinomas epidermoides; el pilar del tratamiento es el quirúrgico, puede tornarse multidisciplinario; con radio/quimioterapia. Las opciones quirúrgicas son resecciones locales, amplias, incluso amputaciones, y el tratamiento de las metástasis linfáticas; vaciamientos linfocelulares. A continuación se presenta un caso clínico sobre el manejo quirúrgico de una úlcera de Marjolin en un paciente de 29 años.
\end{abstract}

Palabra clave: ulcera de Marjolin.

\section{ABSTRACT}

The concept Marjolin's ulcer, include all malignant processes from scar tissue, $5 \%$ of squamous cell carcinomas; The pillar of treatment is surgical, can become multidisciplinary; With radio / chemotherapy. Surgical options are local, extensive resections, including amputations, and treatment of lymphatic metastases; Lymphocellularemptyings. The following is a case report on the surgical management of a Marjolin ulcer in a 29-year-old patient.

Key word: Marjolin's ulcer.

\section{INTRODUCCIÓN}

La úlcera de Marjolin forma parte de un grupo de neoplasias originadas en la cicatriz de una quemadura, se asocia a la transformación de tejidos superficiales crónicamente in-flamados o traumatizados. Representa entre 2 y $5 \%$ de todos los carcinomas epidermoides de piel. Fue el cirujano francés Jean-Nicholas Marjolin en 1828 quien denominó a esta en-tidad como ulcer chancroides, sin establecer exactamente lo que esto definía. Se debe a DaCosta hacia 1903, el uso del tér-mino de "úlcera de Marjolin" para describir la malignización de una úlcera crónica sobre una cicatriz de quemadura. Se la puede clasificar en dos de acuerdo al tiempo de aparición de la lesión cancerosa: aguda cuando aparece antes de los 5 años de haberse producido la quemadura y crónica cuando aparece 5 años después. Los tipos histológicos más frecuen-tes que se presentan en la úlcera de Marjolin son: Carcinoma
Escamoso, Carcinoma Espinocelular, Carcinoma Basocelular; otros tipos de menor frecuencia: melanoma, sarcomas. La mayor parte de estos tumores se curan con cirugía convencional; sin embargo, alrededor de $5 \%$ tendrán metástasis locales y a distancia, lo que se relaciona con factores de alto riesgo, en los cuales el tratamiento es más complejo, entran en juego la quimioterapia, radioterapia y los diferentes tratamientos quirúrgicos. En cuanto a las metástasis linfáticas, a veces el primer lugar nodal de la enfermedad puede ser la fosa poplítea, éste es un evento infrecuente, si ocurre, la linfadenectomía poplítea radical debe ser llevada a cabo, éstos de difícil detección, ya que se encuentran profundos en la fascia y por ello son de difícil exploración, por esto es de vital importancia resaltar, que, toda lesión en miembros inferiores, que haya hecho metástasis linfática en región inguinal, se debe estudiar a cabalidad los huecos poplíteos, ya que, si bien no es común, es el primer sitio de parada metastásica en la cual se debería pensar, y debe ser llevado a cabo un correcto vaciamiento, respetando los parámetros anatómicos para no producir lesiones y ocasionar disfunciones permanentes.

\section{CASO CLÍNICO}

Paciente de sexo masculino de 29 años de edad, procedente de Caacupé, de profesión Chipero, con antecedente de quemadura en planta de pie derecho a la edad de 2 años, por lo que fue intervenido en dos ocasiones en dicha oportunidad, 27 años después, se percata de lesión ulcero-vegetante, sangrante, dolorosa, bordes irregulares, bien delimitado en talón derecho por lo que se realiza una resección local amplia, con confirmación histológica de carcinoma escamoso ulcerado de piel, pobremente diferenciado, acude nuevamente a consulta con una lesión de $8 \mathrm{~cm}$ de diámetro, ulcerado, sangrante, infectado, con clínica de anemia, confirmada por análisis laboratoriales y dolor, dicha lesión fija a planos profundos con adenopatía múltiple, fija, sólida-pétrea, menor a $1 \mathrm{~cm}$ en región inguinal homolateral de igual estirpe histológica, por lo que se realiza amputación infracondílea

\footnotetext{
* Jefe del Depto. de Cirugía del INCAN

** Jefe de Guardia del INCAN

$* * * \quad$ Residente de 4to. Año del INCAN

$* * * *$ Residente de 3 er Año del INCAN
}

Instituto Nacional del Cáncer, Capiatá- Paraguay, 2016. Dirección Postal: willianovr@hotmail.com roduarteinc@gmail.com Articulo recibido: $11 / 10 / 2016$

Articulo aceptado: 20/11/2016 
de pie derecho mas vaciamiento inguinal homolateral en marzo de 2016, en mayo del mismo año el paciente se percata de tumoración en región poplítea del lado derecho, se constata adenopatía dolorosa, fija, mayor a $1 \mathrm{~cm}$ de aspecto sospechoso por ecografía, se decide vaciamiento poplíteo, que se realiza en mayo del 2016, cuyo reporte de la pieza

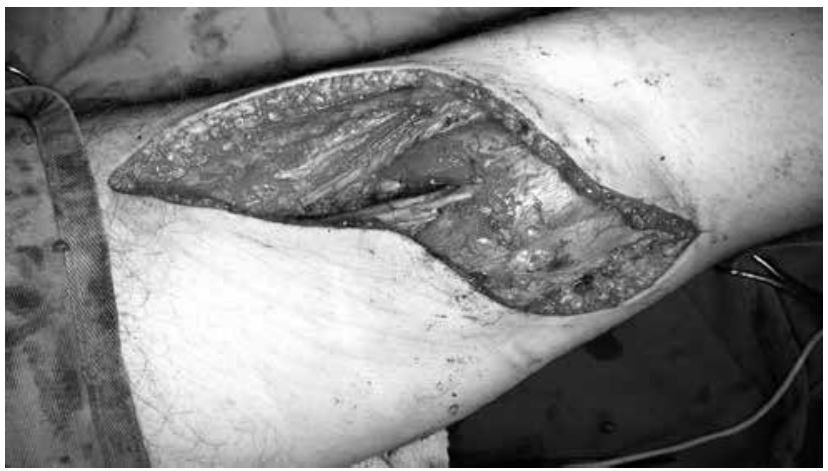

Incisión en S itálica que inicia $10 \mathrm{~cm}$ por encima del hueco poplíteo y se extiende a lo largo del miembro aproximadamente $10 \mathrm{~cm}$ por debajo del mismo.

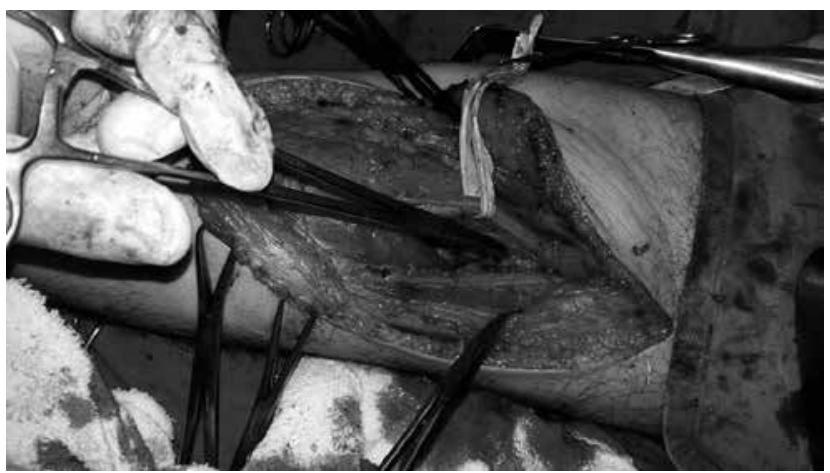

Señalando con un porta agujas podemos observar la arteria poplítea. operatoria informa misma estirpe histológica, confirmando así la metástasis ganglionar en 1 de 3 ganglios linfáticos, actualmente el paciente se encuentra en curso de radioterapia sobre región inguinal, por recaída de metástasis linfática. A continuación se describen los pasos del vaciamiento poplíteo, procedimiento poco común realizado en nuestro servicio, sobre todo en ésta patología:

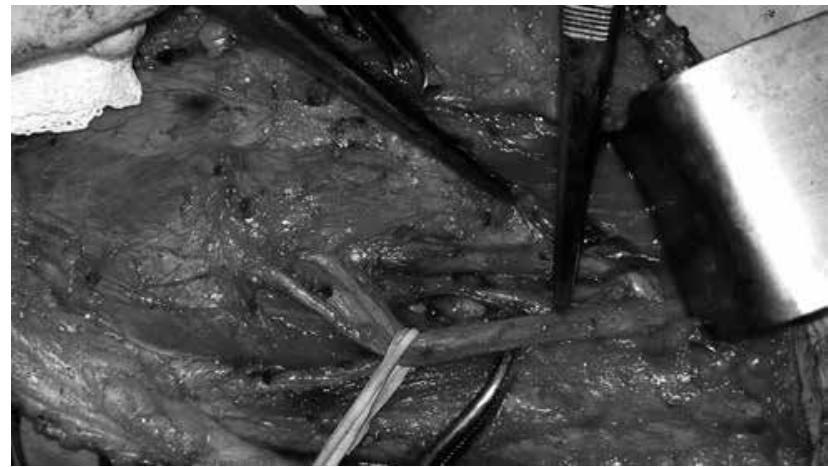

Exposición, identificación y preservación de las estructuras: fascia poplítea, músculos semimembranoso, semitendinoso y bíceps femoral, límites superiores del hueco poplíteo y los músculos gastrocnemios; como límite inferior.

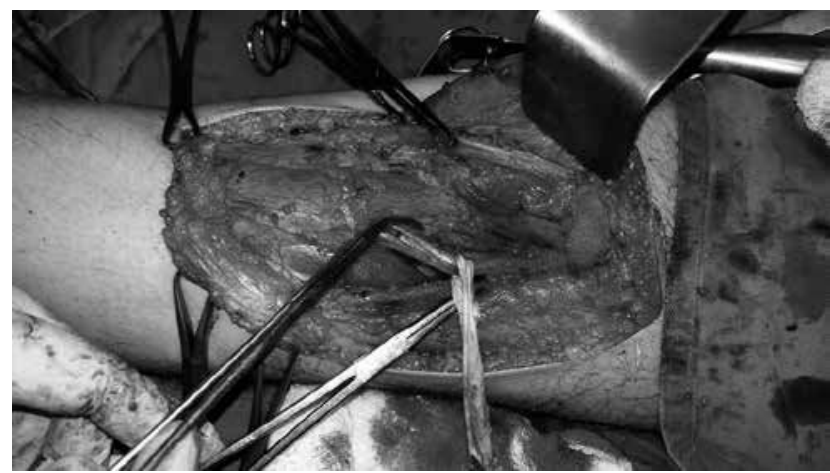

En ésta foto se tracciona con un penrose el nervio tibial y peroneo común, se señala con una cística la vena poplítea.

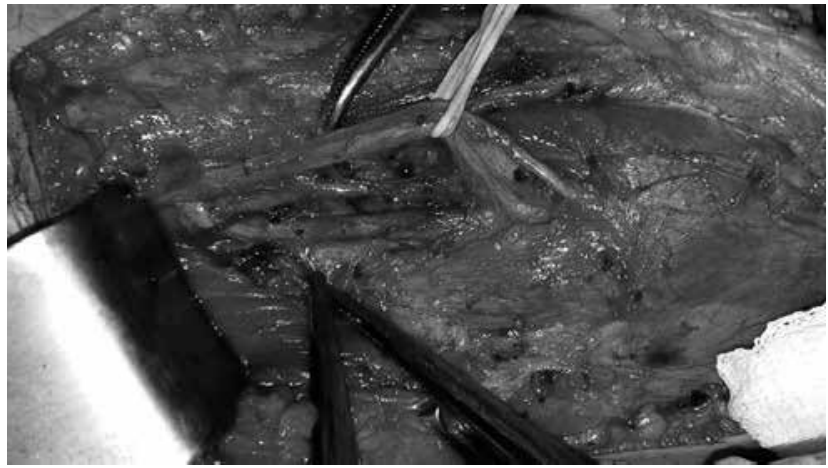

Luego de remover todo el tejido linfático, las estructuras perfectamente visializadas y preservadas 


\section{DISCUSIÓN}

Los carcinomas de alto riesgo son aquellos que tienen un gran porcentaje de recidiva, de metástasis ganglionares o metástasis a distancia, en la actualidad, los factores pronósticos de recidiva además del tamaño tumoral $(>2 \mathrm{~cm})$, para definir a la neoplasia de base de alto riesgo se consideran: la profundidad de invasión $(>2 \mathrm{~mm})$, invasión perineural, invasión linfovascular, grado de diferenciación (tumores mal diferenciados), tipo histológico (desmoplásico, adenoescamoso), origen a partir de un proceso inflamatorio crónico, inmunosupresión concomitante, localización en zonas de alta recidiva (pabellón auricular, mucosa labial) y expresión de marcadores histológicos y genéticos asociados con comportamiento agresivo (EGFR, STAT-3, E-caderina, CD44), el paciente en cuestión presenta varios de éstos criterios, motivo por el cual recayó en enfermedad metastásica ganglionar con criterios de resecabilidad, La amputación se reserva para los casos con afectación local de los espacios articulares, invasión ósea o invasión local profunda extensa, siendo éste último el criterio para la segunda cirugía llevada a cabo en nuestro paciente, aunque la disección ganglionar es motivo de controversia, ya que es no mejora la sobrevida en un gran porcentaje, es llevada a cabo en dos ocasiones en nuestro pa- ciente por ser el único foco de recaída; en cuanto a la radioterapia y quimioterapia (metotrexato, bleomicina y cisplatino) se indica para pacientes con mal pronóstico o metástasis a distancia. La radioterapia es el método de elección en pacientes ancianos cuando existe alguna contraindicación quirúrgica y es útil cuando la cirugía convencional puede conllevar secuelas funcionales o cosméticas importantes. La sobrevida libre de enfermedad está ampliamente relacionada con la detección temprana, la correcta técnica quirúrgica empleada, la disección meticulosa, la exéresis completa de la lesión, tanto primaria como metastásica, y el adecuado seguimiento y acompañamiento del paciente.

Una vez diagnosticada la enfermedad, son muchos los puntos a tener en cuenta a la hora de la toma de decisión de la conducta a seguir, sabiendo que la quirúrgica es la base de la curación de la enfermedad en casos de detección temprana.

La metástasis ganglionar es el factor pronóstico más importante para predecir la evolución de la enfermedad, en caso de que esto ocurriese, es allí en donde entra en juego el papel multidisciplinario del tratamiento.

La elección del esquema de tratamiento dependerá exclusivamente de las condiciones del paciente al momento del diagnóstico.

\section{REFERENCIAS}

1. Sergio Renato Pais Costa; Sergio Henrique Couto Horta; Alexandre Cruz Henriques; Popliteal lymphadenectomy for treating metastatic melanoma: case report, July 2008; vol.126; Pág.: 1, 2; Sao Paulo Med. J. no.4.

2. Miguel Ángel Cardona Hernández; Leonel Fierro-Arias; Maribet González-González; Leopoldo-Ávila Medrano; Carcinoma epidermoide de alto riesgo originado en úlcera de Marjolin. Tratamiento alternativo con radioterapia; Dermatol Rev Mex; 2014; 58:267-273.

3. Hugo Marone; Corrado Caracò; Maria Grazia Chiofalo; Gerardo Botti; Nicola Mozzillo; Resección en la fosa poplítea para el melanoma metastásico; World Journal of Surgical Oncology; Instituto Nacional del Cáncer de Ná-

poles, Italia, 2007; 5: 8-8.

4. Irene García Morales; Amalia Pérez; Francisco M, Camacho; Úlcera de Marjolin: carcinoma sobre cicatriz por quemadura , Actas Dermosifiliogr , Sevilla-España, 2006;97:529-32 - Vol. 97 Núm.8.

5. Enrique J. Moya Rosa, Úlcera de Marjolim, Hospital Universitario Manuel Ascunce Domenech. Camagüey, Cuba, AMC vol.16 no.5 Camagüey sep.-oct. 2012, version on line.

6. Vanessa O. Zagne Bauk; Aline Mesquita Assunção; Renata Ferreira Domingues; Nurimar C. Fernandes; Tullia Cuzzi Maya; Juan Piñeiro Maceira, Úlcera de Marjolin: relato de 12 casos, Dermatología. vol.81 no.4 Rio de Janeiro Julio/Agosto. 2006 